\title{
p38 MAP kinase activation by Clostridium difficile toxin A mediates monocyte necrosis, IL-8 production, and enteritis
}

\author{
Michel Warny, ${ }^{1}$ Andrew C. Keates, ${ }^{1}$ Sarah Keates, ${ }^{1}$ Ignazio Castagliuolo, ${ }^{1}$ \\ Jeff K. Zacks, ${ }^{2}$ Samer Aboudola, ${ }^{1}$ Amir Qamar, ${ }^{1}$ Charalabos Pothoulakis, ${ }^{1}$ \\ J. Thomas LaMont, ${ }^{1}$ and Ciarán P. Kelly ${ }^{1}$ \\ ${ }^{1}$ Gastroenterology Division, Beth Israel Deaconess Medical Center, Harvard Medical School, \\ Boston, Massachusetts 02215, USA \\ ${ }^{2}$ Mallory Institute of Pathology, Boston University Medical Center, Boston, Massachusetts 02118, USA
}

Address correspondence to: Michel Warny, Gastroenterology Division, Dana Building, Room 501, Beth Israel Deaconess Medical Center, Harvard Medical School, 330 Brookline Avenue, Boston, Massachusetts 02215, USA. Phone: (617) 667-1944; Fax: (617) 667-2767; E-mail: mwarny@caregroup.harvard.edu.

Received for publication June 9, 1999, and accepted in revised form February 29, 2000.

Clostridium difficile toxin A causes acute neutrophil infiltration and intestinal mucosal injury. In cultured cells, toxin A inactivates Rho proteins by monoglucosylation. In monocytes, toxin A induces IL-8 production and necrosis by unknown mechanisms. We investigated the role of mitogen-activated protein (MAP) kinases in these events. In THP-1 monocytic cells, toxin A activated the 3 main MAP kinase cascades within 1 to 2 minutes. Activation of $\mathrm{p} 38$ was sustained, whereas stimulation of extracellular signal-regulated kinases and c-Jun $\mathrm{NH}_{2}$-terminal kinase was transient. Rho glucosylation became evident after 15 minutes. IL-8 gene expression was reduced by $70 \%$ by the MEK inhibitor PD 98059 and abrogated by the p38 inhibitor SB203580 or by overexpression of dominant-negative mutants of the p38-activating kinases MKK3 and MKK6. SB203580 also blocked monocyte necrosis and IL-1 $\beta$ release caused by toxin A but not by other toxins. Finally, in mouse ileum, SB203580 prevented toxin A-induced neutrophil recruitment by $92 \%$ and villous destruction by $90 \%$. Thus, in monocytes exposed to toxin A, MAP kinase activation appears to precede Rho glucosylation and is required for IL-8 transcription and cell necrosis. p38 MAP kinase also mediates intestinal inflammation and mucosal damage induced by toxin A.

J. Clin. Invest. 105:1147-1156 (2000).

\section{Introduction}

Clostridium difficile causes antibiotic-associated diarrhea and pseudomembranous colitis in humans (1). Pathogenic strains of $C$. difficile release 2 large exotoxins: toxin A $(308 \mathrm{kDa})$ and toxin B $(269 \mathrm{kDa})$. In animal models, only toxin $\mathrm{A}$ is enterotoxic and causes fluid secretion, mucosa edema, and villous disruption by inducing massive acute inflammation with neutrophil infiltration. We have shown that blocking neutrophil extravasation using an anti-CD18 antibody prevented toxin A-induced enteritis and mucosal damage (2).

Toxin A and toxin B show 63\% homology (3) and share similar domains. Their $\mathrm{COOH}$-terminal portions carry repeating sequences that may be involved in receptor binding. The $\mathrm{NH}_{2}$-terminal portions carry an enzymatic domain, which hydrolyzes UDP-glucose and transfers the glucose moiety to a conserved threonine residue of the small GTP-binding proteins Rho, $\mathrm{Cdc} 42$, and Rac (4-6). The small GTP-binding protein Rap is glucosylated only by toxin A (7). These covalent modifications inactivate Rho proteins, which in turn induce cytoskeleton disaggregation and cell rounding. Whether Rho glucosylation is involved in toxin A enterotoxicity and in vitro cytokine production is not known. Toxin A or toxin $\mathrm{B}$ were shown to block Rho-regulated signaling pathways, including basophilic cell activation (8), receptor signaling to phospholipase D (9), NF- $\mathrm{\kappa B}$ activation by bradykinin (10), and mitogen-activated protein-kinase (MAP kinase) activation $(11,12)$. Blockage of the above signal transduction pathways by C. difficile toxins is consistent with the role of Rho proteins in signaling to MAP kinases and NF- $\mathrm{KB}(13-15)$. However, it appears at variance with the known in vivo and in vitro inflammatory actions of toxin A.

In cells of the monocyte lineage, $C$. difficile toxins stimulate inflammatory cytokine release, including TNF- $\alpha$, IL-1 $\beta$, IL-6, and IL-8 (16-18). In addition, we have reported recently that both toxins induce necrosis in human monocytes and in THP-1 human monocytic cells. This cell-death pathway is associated with potassium depletion, caspase activation, and maturation and release of preformed IL-1 $\beta$ (19). The mechanisms whereby these toxins activate and kill monocytes are not known.

In this study, we investigated the role of MAP kinases in IL-8 production, IL-1 $\beta$ release, and necrosis induced by toxin A in monocytic cells. MAP kinases regulate cell responses to growth factors and stress stimuli and transmit signals from the cell surface to the nucleus via 3 distinct but related pathways. These culminate in the selective activation of extracellular signal-related kinases (ERK), p38, and c-Jun $\mathrm{NH}_{2}$-terminal kinase (JNK) 
(20-23). All 3 signaling cascades have been implicated in the control of apoptosis and cytokine transcription. Here we report that p38 MAP kinase plays a key role in monocyte activation, monocyte necrosis, and enteritis induced by C. difficile toxin A.

\section{Methods \\ C. difficile toxin A}

Toxin A was purified from C. difficile strain VPI 10463 (American Type Culture Collection, Rockville, Maryland, USA). Culture supernatant was fractionated by anionexchange chromatography, and toxin A was isolated by precipitation in acetate buffer as described previously (24). Toxin A was further purified by fast-protein liquid chromatography (FPLC) using a MonoQ column (Pharmacia Biotech Inc., Piscataway, New Jersey, USA). Buffers were prepared using LPS-free water (Baxter Healthcare Corp., Deerfield, Illinois, USA), and LPS activity in toxin A solutions $(3-4 \mathrm{mg} / \mathrm{mL})$ was less than 1 endotoxin unit/mL (quantitative chromogenic limulus amebocyte lysate; BioWhittaker, Walkersville, Maryland, USA).

Cells

Human monocytic THP-1 cells (American Type Culture Collection) were grown in RPMI-1640 supplemented with 5\% FBS, $10 \mathrm{mM}$ HEPES, $50 \mathrm{mmol} \beta$-mercaptoethanol, $50 \mathrm{U} / \mathrm{mL}$ penicillin $\mathrm{G}$, and $50 \mu \mathrm{g} / \mathrm{mL}$ streptomycin (GIBCO BRL, Grand Island, New York, USA), in a humid atmosphere containing $5 \% \mathrm{CO}_{2}$. Human monocytes were isolated from peripheral blood and cultured in the same medium. Blood was diluted 1:2 by volume in PBS and $20 \mathrm{~mL}$ was layered on $15 \mathrm{~mL}$ Histopaque (Sigma, St. Louis, Missouri, USA). After centrifugation (500 $\mathrm{g}$ for 20 minutes), mononuclear cells were washed 4 times in RPMI/10 mM HEPES/0.1 $\% \mathrm{BSA} / 1 \mathrm{mM}$ EDTA, resuspended in culture medium, and incubated in tissue-culture plates (Primaria, Falcon; Becton Dickinson and Co., Franklin Lakes, New Jersey, USA). Nonadherent cells were washed away after 15 minutes. Adherent cells (> $80 \%$ monocytes, as determined by FACS analysis) were cultured overnight, and fresh medium was added before stimulation. Higher toxin A concentrations were used to stimulate THP-1 cells than in experiments using primary human monocytes in accordance with our previous report (18).

\section{MAP kinase assays}

Before stimulation, THP-1 cells were cultured overnight in serum-free medium $\left(7 \times 10^{5}\right.$ cells $\left./ \mathrm{mL}\right)$. After stimulation by toxin $\mathrm{A}(100 \mathrm{nM})$ for varying time periods cells, were placed in ice-cold PBS.

MAP kinase phosphorylation assay. THP- 1 cells $\left(5 \times 10^{6}\right)$ were resuspended in $200 \mu \mathrm{LSDS}$-PAGE sample buffer and boiled for 5 minutes. Cell extracts were separated by SDSPAGE (12\%), and proteins were transferred onto polyvinyldene fluoride membranes (Immobilon P; Millipore Corp., Bedford, Massachusetts, USA). Membranes were blocked in 5\% nonfat, dried milk in PBS and probed with phosphospecific antibodies $(0.2 \mu \mathrm{g} / \mathrm{mL})$ to ERK $1 / 2$, p38 $\alpha$ (New England Biolabs, Beverly, Massachusetts, USA), and JNK 1 (catalogue no. sc-6254; Santa Cruz Biotechnology Inc., Santa Cruz, California, USA). Horseradish peroxidase-labeled antibodies were detected by chemiluminescence using the ECL kit (Amersham Life Sciences Inc., Arlington Heights, Illinois, USA).

In vitro kinase assay. THP- 1 cells $\left(5 \times 10^{6}\right)$ were lysed in $1 \mathrm{~mL}$ lysis buffer $(150 \mathrm{mmol} \mathrm{NaCl}, 1 \%$ Nonidet P-40, $0.8 \mathrm{mmol} \mathrm{MgCl} 2,5 \mathrm{mmol}$ EGTA, $1 \mathrm{mmol} \mathrm{Na} \mathrm{VO}_{4}, 15$ $\mu \mathrm{g} / \mathrm{mL}$ leupeptin, $1 \mathrm{mmol}$ PMSF, $50 \mathrm{mmol}$ HEPES, $\mathrm{pH}$ 7.5). MAP kinases were precipitated with $2 \mu \mathrm{g}$ rabbitspecific IgG to ERK2 (sc-154), p38 (sc-535), or JNK1 (sc-571) (Santa Cruz Biotechnology Inc.). After incubation for 2 hours at $4^{\circ} \mathrm{C}, 20 \mu \mathrm{L}$ protein G-Sepharose (Santa Cruz Biotechnology) was added, and samples were further incubated for 1 hour. Immunopellets were washed twice in lysis buffer, twice in kinase buffer (30 $\mathrm{mM} \mathrm{NaCl}, 0.1 \mathrm{mM} \mathrm{Na}_{3} \mathrm{VO}_{4}, 2 \mathrm{mM} \mathrm{DTT}, 20 \mathrm{mM} \mathrm{MgCl}_{2}$, $30 \mathrm{mmol}$ HEPES, $\mathrm{pH}$ 7.5) and then resuspended in 40 $\mu \mathrm{L}$ kinase buffer. The kinase reaction was started by addition of $20 \mu \mathrm{M}$ ATP, $100 \mu \mathrm{Ci} / \mathrm{mL}\left[\gamma^{-32} \mathrm{P}\right]$ ATP (Dupont NEN Life Sciences, Boston, Massachusetts, USA), and $10 \mu \mathrm{g}$ myelin basic protein (Sigma) as substrate for ERK and p38, and $2 \mu \mathrm{g}$ GST c-Jun (1-79) (Stratagene, La Jolla, California, USA) as substrate for JNK1. Samples were subjected to SDS-PAGE (12\%) and analyzed using autoradiography.

\section{Luciferase IL-8 reporter gene assay}

A 1521-bp fragment containing nucleotides -1481 to +40 of the promoter region of the IL- 8 gene was cloned into the pGL2-basic luciferase expression vector between KpnI and HindIII restriction sites. The sequences were confirmed by DNA sequencing using primers specific for the pGL2-basic luciferase expression vector (GL primers 1 and 2; Promega Corp., Madison, Wisconsin, USA). THP-1 cells were transiently transfected using the DEAE-dextran procedure. Briefly, $2 \times 10^{7}$ THP- 1 cells were suspended in 1 $\mathrm{mL}$ prewarmed Tris-buffered saline and incubated for 10 minutes at $37^{\circ} \mathrm{C}$ with $80 \mu \mathrm{g}$ DEAE-dextran (Pharmacia). For single-plasmid transfection, THP-1 cells were transfected with $5 \mu \mathrm{g}$ DNA of the luciferase IL-8 reporter plasmid. In cotransfection experiments, total DNA was kept constant at $7 \mu \mathrm{g}$ using control vector, and $1 \mu \mathrm{g}$ of reporter plasmid DNA was transfected. Transfection was stopped by adding $25 \mathrm{~mL}$ Trisbuffered saline. After washing, cells were cultured for 48 hours before stimulation. After stimulation, THP1 cells $\left(2 \times 10^{6}\right.$ cells per stimulus) were washed in PBS. Cell lysis and luciferase assay were performed using the Luciferase Assay System from Promega Corp. following the instructions of the manufacturer. All transfection experiments were performed in triplicate. The plasmids encoding the dominant-negative mutants of MKK3 and MKK6 were kindly provided by Roger Davis (University of Massachusetts Medical School, Worcester, Massachusetts, USA). 
After toxin A exposure, $5 \times 10^{6}$ THP- 1 cells or cultured monocytes isolated from $10 \mathrm{~mL}$ blood was centrifuged and resuspended in $50 \mu \mathrm{L}$ lysis buffer (50 mmol Tris, 3 mmol $\mathrm{MgCl}_{2}, 0.5$ mmol PMSF, pH 7.5) and a cocktail of protease inhibitors (Complete; Boehringer Mannheim Biochemicals, Mannheim, Germany). Cells were frozen $\left(-70^{\circ} \mathrm{C}\right)$ and thawed $\left(20^{\circ} \mathrm{C}\right)$ twice and then centrifuged at $14,000 \mathrm{~g}$ for 5 minutes to pellet-insoluble materials. The Clostridium botulinum C3-catalyzed ADP-ribosylation of Rho was initiated by adding $30 \mu \mathrm{L}$ extract to $10 \mu \mathrm{L}$ of $5 \times \mathrm{C} 3$ buffer $(250 \mathrm{mM}$ triethanolamine, $\mathrm{pH} 7.5,10 \mathrm{mM}$ $\mathrm{MgCl}_{2}, 5 \mathrm{mM}$ EDTA, $5 \mathrm{mM}$ DTT, and $1 \mathrm{mM} \mathrm{PMSF}$ ), $10 \mu \mathrm{M}\left[{ }^{32} \mathrm{P}\right] \mathrm{NAD}$ (Dupont NEN), and $1 \mu \mathrm{g} / \mathrm{mL} \mathrm{C} 3$ (Biomol Research Laboratories, Plymouth Meeting, Pennsylvania, USA) in a final volume of $50 \mu \mathrm{L}$ (5). After incubation for 30 minutes at $30^{\circ} \mathrm{C}$, the reaction was stopped by addition of $12.5 \mu \mathrm{L}$ of $5 \times$ Laemmli buffer, and samples were boiled for 5 minutes. Extracts were subjected to $12 \%$ SDS-PAGE, and ADPribosylated Rho was quantified by autoradiography and densitometry.

Cytokine assays

IL-8 concentration was determined by ELISA using goat anti-human IL-8 (R \& D Systems Inc., Minneapolis, Minnesota, USA) as described previously (18). IL-1 $\beta$ was measured using a commercial ELISA (Cistron Biotechnology, Pine Brooks, New Jersey, USA).

\section{Figure 1}

C. difficile toxin A activates ERK 1/2, p38, and JNK1 in THP-1 monocytic cells. THP- 1 cells were stimulated with toxin A (100 nM) for various periods of time. ERK 1/2 (a), p38 (b), and JNK1 (c) activities were measured by immunoblotting using phosphospecific antibodies (upper panels). The enzymatic activities of ERK2, p38, and JNK1 were measured by in vitro kinase assays after immunoprecipitation (lower panels). Myelin basic protein (MBP) was used as substrate for ERK2 and p38, and GST-c-Jun 1-79 $_{\text {was }}$ used for JNK1. Toxin A induced rapid (12 minutes) activation of ERK1/2, p38, and JNK1. After 1-hour incubation, p38 activity was increased 6.7-fold as determined by densitometry, whereas ERK and JNK activities had returned to control levels. (d) ERK2 and p38 kinase activities were measured in THP-1 cells either 2 minutes (for ERK2) or 30 minutes (for p38) after stimulation with toxin $\mathrm{A}(100 \mathrm{nM})$. Pretreatment with the MEK1/2 inhibitor PD98059 (20 $\mu \mathrm{M})$ for 30 minutes prevented ERK2 activation, whereas pretreatment with the p38 inhibitor SB203580 $(10 \mu \mathrm{M})$ blocked p38 kinase activity.

\section{Effect of SB203580 on toxin A-induced enteritis}

Fasted (16 hours) mice (C57BL; Charles River Laboratories, Wilmington, Massachusetts, USA) were anesthetized by intraperitoneal injection of sodium pentobarbital $(600 \mu \mathrm{g} /$ mouse). Ileal loops $(3-4 \mathrm{~cm})$ were prepared and injected with buffer alone, with the specific p38 inhibitor SB203580-hydrochloride (100 $\mu \mathrm{g}$ in water), or with SB202474, an inactive analogue $(100 \mu \mathrm{g}$ in $5 \mathrm{mM} \mathrm{Hcl}$ ) (Calbiochem-Novabiochem Corp., San Diego, California, USA), in a volume of $200 \mu \mathrm{L}$. After 30 minutes, toxin A $(10 \mu \mathrm{g}$ in PBS) was injected into the loops, and animals were sacrificed 4 hours later by pentobarbital overdose. Loops were cut out and weighed, and length was measured. Fluid secretion was expressed as the loop weight-to-length ratio $(\mathrm{mg} / \mathrm{cm})$. Ileal tissue samples were fixed in formalin, paraffin embedded, and stained with hematoxylin and eosin. Tissue sections were examined by a pathologist in a blinded fashion, using a scoring system as described previously (25). Toxin A-induced enteritis was graded by scoring (from 0 to 3) 3 parameters: (a) disruption of villus architecture (b) mucosal congestion, and (c) neutrophil infiltration. This study was approved by Beth Israel Deaconess Medical Center Animal Care and Use Committee (Boston, Massachusetts, USA).

Statistical analyses

Results are represented as means and SE. Statistical analyses were performed using the SIGMA-STAT soft-

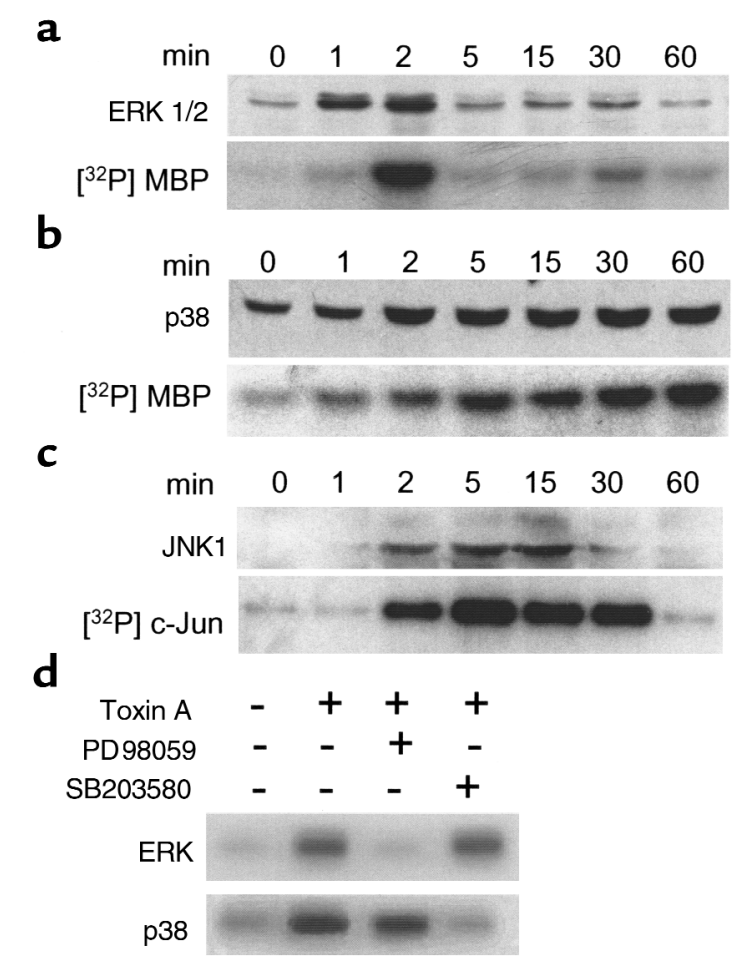


ware (Jandel Scientific, San Raphael, California, USA). ANOVA with protected $t$ test was used for intergroup comparison.

\section{Results}

C. difficile toxin A activates ERK 1/2, p38, and JNK1 kinases in monocytic cells. We have shown previously that $C$. difficile toxin A stimulates IL-8 production and release in normal monocytes and in THP- 1 cells, a human monocytic cell line (18). However, the signal transduction mechanisms activated in monocytic cells by toxin A are not known. Because MAP kinases regulate cell survival and cytokine production in response to stress, we measured MAP kinase phosphorylation and enzymatic activity in THP- 1 cells exposed to purified toxin A (100 $\mathrm{nM}$ ) at various time points. As shown in Figure 1, toxin A strongly activated phosphorylation and enzymatic activity of ERK2, p38, and JNK1. ERK1 was also activated, but to a lesser extent. All 3 MAP kinase pathways were activated within 1 to 2 minutes of stimulation, but the duration of activation was quite different. As
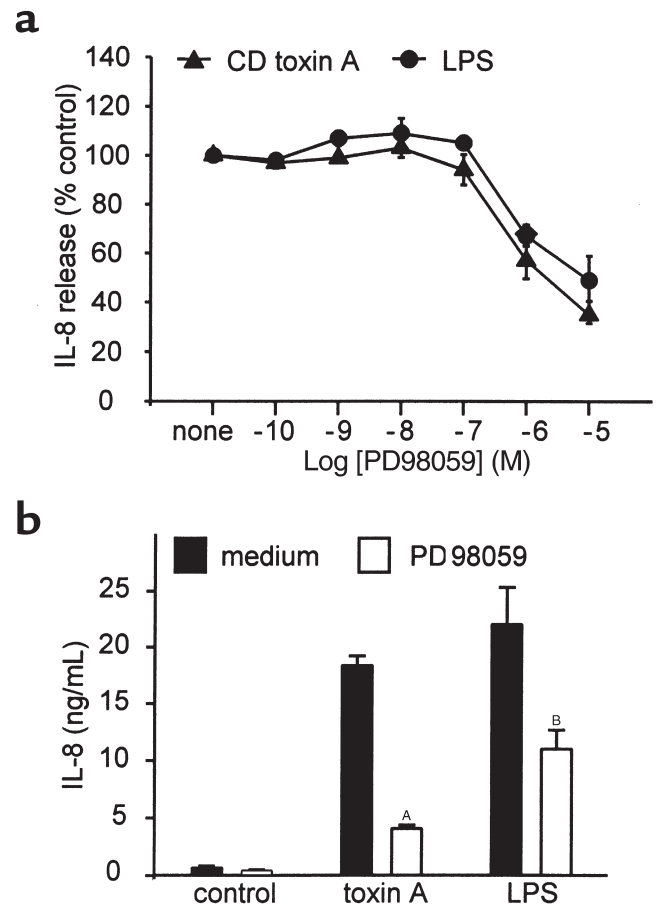

\section{Figure 2}

The ERK pathway is required for toxin A-induced IL-8 release. (a) THP-1 cells $\left(10^{6} / \mathrm{mL}\right)$ were preincubated with various concentrations of the MEK inhibitor PD98059 for 30 minutes. Then, cells were stimulated with $C$. difficile toxin A $(100 \mathrm{nM})$ or LPS $(1 \mu \mathrm{g} / \mathrm{mL})$ for 4 hours. PD98059 partially inhibited IL- 8 release induced by toxin $A$ and by LPS (IC 50,2 and $10 \mu \mathrm{M}$, respectively). Mean $\pm \mathrm{SE}$ is shown $(n=3)$. (b) Peripheral blood monocytes were incubated in the presence of PD98059 for 30 minutes and then stimulated for 4 hours with $C$. difficile toxin A ( $2 \mathrm{nM})$ or LPS $(1 \mu \mathrm{g} / \mathrm{mL})$. PD98059 significantly reduced IL-8 production by both stimuli. Results are expressed as means and $\mathrm{SE}\left(n=3 ;{ }^{\mathrm{A}} P<0.001 ;{ }^{\mathrm{B}} P<0.05\right)$. observed in 3 separate experiments, ERK activity peaked after 2-4 minutes and returned to control levels after 5 minutes. JNK1 activity returned to control level after 30-60 minutes, whereas p38 remained highly activated after 1 hour of stimulation. These results show that $C$. difficile toxin A activates all 3 MAP kinase pathways and that the profile of activation is characterized by a strong and sustained activation of $\mathrm{p} 38$.

The ERK and $p 38$ pathways are required for toxin $A$-induced IL-8 release. To evaluate the biological significance of MAP kinase activation in toxin A-induced IL8 release, we examined the effect of PD98059, which inhibits MEK1/2, a MAP kinase that phosphorylates ERK1/2. In control experiments, PD98059 prevented toxin A-induced ERK2 activation in THP-1 cells as determined by in vitro kinase assay, but had no significant effect on p38 kinase activity (Figure 1d). Conversely, the p38 inhibitor SB203580 blocked toxin A-induced p38 kinase activity without preventing the activation of ERK2 (Figure 1d).

As shown in Figure 2a, pretreatment of THP-1 cells with PD98059 for 30 minutes inhibited IL-8 release induced by toxin $\mathrm{A}$ ( $100 \mathrm{nM}$ for 4 hours). The effect was dose dependent $\left(\mathrm{IC}_{50}, 2 \mu \mathrm{M}\right)$, and $10 \mu \mathrm{m}$ PD98059 inhibited toxin A-induced IL-8 release by $70 \%$. The $\mathrm{IC}_{50}$ for LPS-stimulated IL-8 production was $10 \mu \mathrm{M}$. In normal monocytes, PD98059 $(20 \mu \mathrm{M})$ inhibited toxin A (2 $\mathrm{nM})$, and LPS $(1 \mu \mathrm{g} / \mathrm{mL})$ induced IL-8 production by 82 and $52 \%$, respectively (Figure $2 \mathrm{~b}$ ).

We also examined the effect of the pyridinyl imidazole SB203580, which specifically inhibits p38 (22) and p38 $\beta$ (26), but not the p38 $\gamma(27)$ or p38 $\delta$ (28). Cell pretreatment for 30 minutes prevented toxin $\mathrm{A}$-induced IL-8 release in a dose-dependent fashion ( $\mathrm{IC}_{50}, 30 \mathrm{nM}$ ) (Figure 3a). SB203580 $(10 \mu \mathrm{M})$ caused $95 \%$ inhibition of IL-8 production in response to toxin A in THP-1 cells (Figure 3a) and 98\% inhibition in monocytes (Figure 3b). Interestingly, SB203580, when preincubated for 30 minutes, did not inhibit IL-8 production stimulated by LPS $(1 \mu \mathrm{g} / \mathrm{mL})$. However, when preincubated for a longer period (1 or 2 hours), SB203580 inhibited LPS-mediated IL- 8 production by over $86 \%$ whereas its potency on toxin A effects was not increased (Figure $3 c)$. The basis of these differences has not been investigated but may reflect a requirement for higher intranuclear levels of the inhibitor to block the effects of LPS. SB202474, an analogue of SB203580 that does not inhibit p38 kinase activity, did not prevent IL-8 release induced by either stimulus (Figure 3 ). These data indicate that the ERK- and p38-signaling pathways regulate C. difficile toxin A-induced IL-8 release in monocytes.

The ERK and $p 38$ pathways regulate toxin A-induced IL-8 gene expression. To further define the role of MAP kinase activation in toxin A-induced IL-8 production, we tested whether the ERK and p38 pathways were acting at a transcriptional level in THP-1 cells transiently transfected with an IL-8 reporter gene. After pretreatment with 20 $\mu \mathrm{M}$ PD98059 or $10 \mu \mathrm{M}$ SB203580 for 30 minutes, cells were stimulated with toxin A $(100 \mathrm{nM})$ or LPS $(1 \mu \mathrm{g} / \mathrm{mL})$ 


\section{Figure 3}

The p38 inhibitor SB203580

prevents IL- 8 synthesis induced by $\mathrm{C}$. difficile toxin $\mathrm{A}$. (a) THP- 1 cells $\left(10^{6} / \mathrm{mL}\right)$ were preincubated with various concentrations of the p38 inhibitor SB203580 for 30 minutes. Then, cells were stimulated for 4 hours with $C$. difficile toxin $A(100 \mathrm{nM})$ or LPS $(1 \mu \mathrm{g} / \mathrm{mL})$. SB203580 blocked IL- 8 release induced by toxin $\mathrm{A}\left(\mathrm{IC}_{50}, 20 \mathrm{nM}\right)$, but did not prevent IL-8 release mediated by LPS. (b) Peripheral blood monocytes were preincubated with SB203580

$(10 \mu \mathrm{M})$ for 30 minutes and then stimulated for 4 hours with $C$. difficile toxin A (2 $\mathrm{nM})$ or LPS $(1 \mu \mathrm{g} / \mathrm{mL})$. SB203580 abrogated toxin A-induced IL- 8 release, but did not affect LPS-induced IL- 8 production. Means and SE are shown $\left(n=3 ;{ }^{A} P=0.002\right)$. (c) THP1 cells $\left(10^{6} / \mathrm{mL}\right)$ were preincubated with $10 \mu \mathrm{M} \mathrm{SB} 203580$ for 30 ,

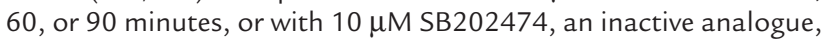
for 60 minutes. Then, cells were stimulated for 4 hours with $C$. difficile toxin A (100 nM) or LPS $(1 \mu \mathrm{g} / \mathrm{mL})$. Inhibition of LPS-induced IL-8 release by SB203580 was observed when preincubated for 60 minutes, whereas 30 minutes was sufficient to prevent toxin A-induced IL-8 release. SB202474 was inactive $\left(n=2\right.$; $\left.{ }^{A} P<0.01\right)$. b

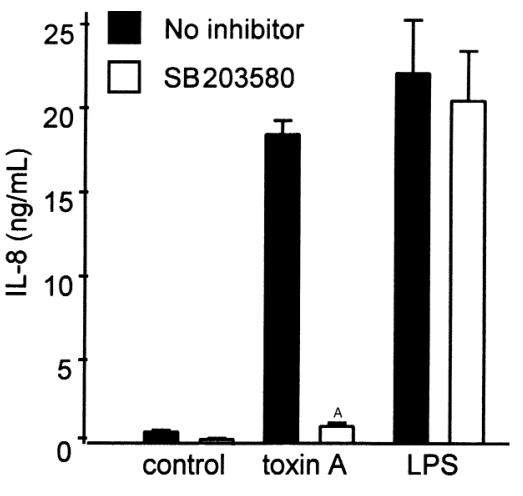

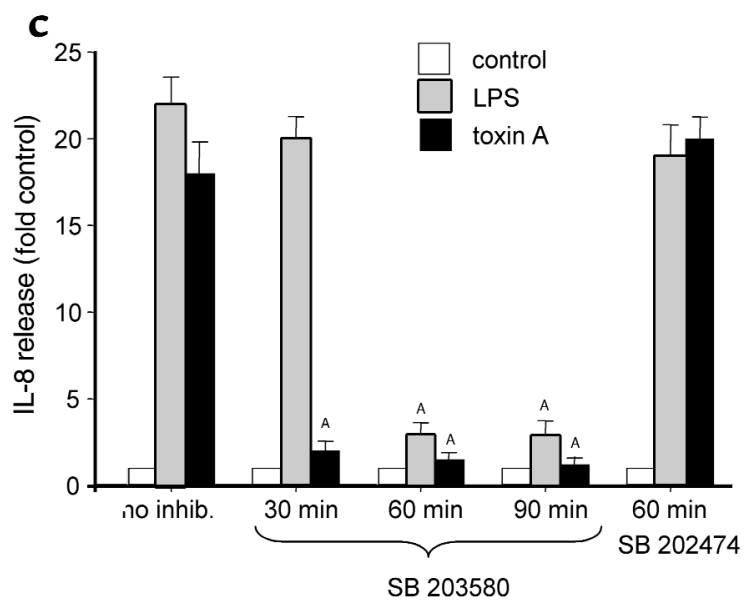

for 4 hours. PD98059 reduced IL-8 gene expression by $70 \%$, and SB203580 completely blocked luciferase activity stimulated by toxin A but not by LPS (Figure 4b). However, when preincubated for 1 hour, SB203580 prevented LPS-induced IL-8 gene expression by $68 \%$. SB202474, an inactive homologue, had no effect (data not shown). These findings indicate that the ERK and $\mathrm{p} 38$ pathways regulate IL-8 gene expression in response to toxin $\mathrm{A}$.

To confirm the role of the p38 pathway in this system, THP-1 cells were cotransfected with dominantnegative mutants of MKK3 and/or MKK6, 2 direct upstream regulators of p38 (27). Whereas each of these plasmids used alone did not significantly inhibit IL-8 gene expression, transfection of both MKK3 and MMK6 abrogated IL- 8 gene expression induced by toxin A (Figure 4c) or LPS.

Monocyte necrosis induced by toxin $A$ is mediated by the ERK and p38 MAP kinase pathways. We have shown recently that $C$. difficile toxin A causes cell necrosis in both monocytes and THP-1 cells (19). This cell-death pathway is induced within 2-3 hours by $10 \mathrm{nM}$ toxin $\mathrm{A}$. Because MAP kinases were implicated in the control of cell survival in various models of stress, we examined their role in monocyte necrosis induced by toxin A. Two other inducers of necrosis in monocytes Staphylococcus aureus $\alpha$-toxin, a pore-forming toxin, and nigericin (19) were used as controls. Peripheral blood

monocytes were cultured as described in Methods and incubated in medium alone or in the presence of PD98059 $(10 \mu \mathrm{M})$ or SB203580 $(10 \mu \mathrm{M})$ for $30 \mathrm{~min}-$ utes. As shown in Figure 5a, addition of C. difficile toxin A $(40 \mathrm{nM})$ or $S$. aureus $\alpha$-toxin $(10 \mathrm{nM})$ induced identical features of cell necrosis, including cell swelling, cytoplasm translucence, and absence of nuclear fragmentation (data for nigericin not shown). Both PD98059 and SB203580 completely prevented the morphological features of necrosis induced by $C$. difficile toxin A, but not by $S$. aureus $\alpha$-toxin (Figure 5 , a and b) or nigericin (not shown). The inactive analogue SB202474 had no effect (data not shown). Both inhibitors also prevented necrosis-associated loss of cell-membrane permeability as measured by propidium iodide uptake (data not shown).

We have shown that monocyte necrosis induced by diverse stimuli including C. difficile toxin A and S. aureus $\alpha$-toxin is associated with caspase-1-dependent IL-1 $\beta$ maturation and release (19). Both PD98059 and SB203580 prevented IL-1 $\beta$ release in a dose-dependent fashion in monocytes treated with toxin $\mathrm{A}$, but not with $S$. aureus $\alpha$-toxin (Figure $5 \mathrm{c}$ ) ( $\mathrm{IC}_{50}, 1 \mu \mathrm{M}$ and 100 $\mathrm{nM}$, respectively). These findings indicate that toxin A-induced activation of the ERK and p38 MAP kinase pathways is upstream of caspase-1-dependent IL-1 $\beta$ release and monocyte necrosis. 
a

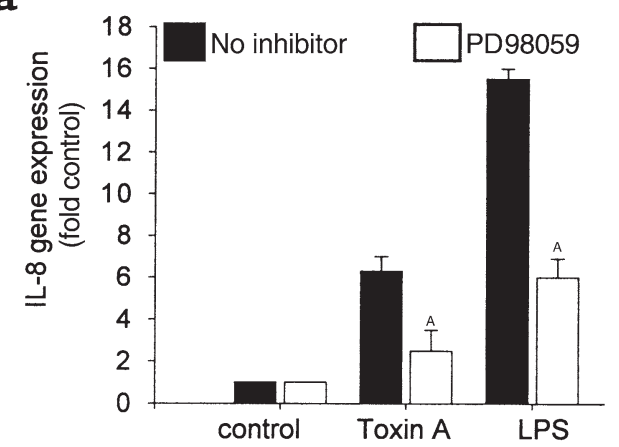

b

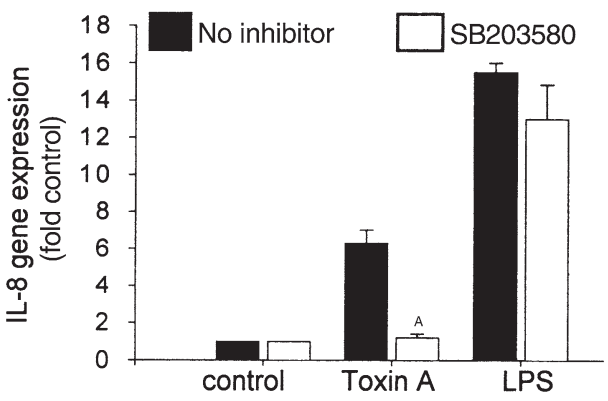

C

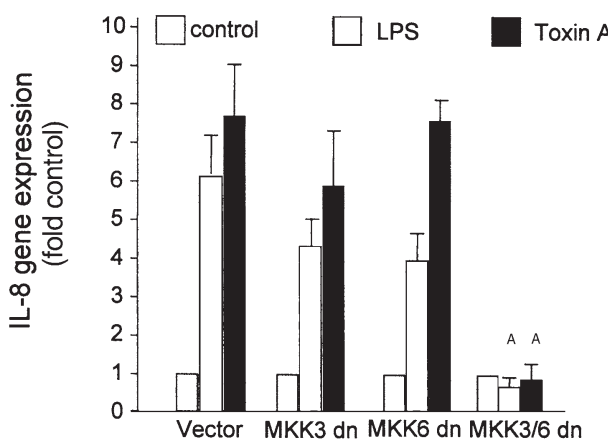

Figure 4

The ERK and $\mathrm{p} 38$ pathways regulate toxin A-induced IL-8 gene expression. (a) THP-1 cells were transiently transfected with a luciferase reporter construct carrying the IL-8 gene promoter region. Then, cells were preincubated with PD98059 $(20 \mu \mathrm{M})$ for 30 minutes and stimulated with $C$. difficile toxin $A(100 \mathrm{nM})$ or LPS $(1 \mu \mathrm{g} / \mathrm{mL})$ for 4 hours. PD98059 prevented IL- 8 gene expression by each stimulus. Means and SE are shown $\left(n=3\right.$; $\left.{ }^{A} P<0.05\right)$. (b) Transfected cells were preincubated with SB203580 (10 $\mu \mathrm{M})$ for 30 minutes and then stimulated with $C$. difficile toxin A (100 $\mathrm{nM})$ or LPS $(1 \mu \mathrm{g} / \mathrm{mL})$ for 4 hours. SB203580 blocked IL-8 gene expression induced by toxin A, but not by LPS $\left(n=3 ;{ }^{A} P=0.003\right)$. (c) The involvement of the $\mathrm{p} 38$ pathway in toxin A-induced IL-8 gene expression was confirmed by transient expression of dominant-negative mutants of MKK3 and MKK6 (MKK3/6 dominant negative $[d n])$. Total DNA was kept constant at $7 \mu \mathrm{g}$ using control vector and included $1 \mu \mathrm{g}$ reporter plasmid DNA. Whereas MKK3 dn or MMK6 dn did not significantly affect IL-8 reporter gene expression, transfection of both mutants abrogated luciferase activity induced by toxin A and by LPS. Means and SE of 2 experiments, each done in triplicate, are shown ( $\left.{ }^{A} P<0.01\right)$.
Toxin-induced MAP kinase activation precedes Rho glucosylation. Having demonstrated that $C$. difficile toxin A activates MAP kinases within 1 to 2 minutes in THP-1 cells, we investigated whether Rho inactivation might trigger this response. We examined the time course of Rho glucosylation in toxin-treated THP-1 cells using the C3-catalyzed ADP-ribosylation assay. The C3 exoenzyme of C. botulinum ADP-ribosylates Rho at the Asn41, and this covalent reaction is inhibited by previous monoglucosylation of Thr37, the residue targeted by toxin A (4). As shown in Figure 6, a significant decrease in ADP-ribosylated Rho was first detected 15-20 minutes after toxin exposure. Because MAP kinase activation occurs within 1 to 2 minutes, Rho glucosylation is unlikely to trigger this early cell response.

In these experiments, a $20 \%$ increase in ADP-ribose incorporation was measured after toxin exposure for 10 minutes (Figure 6). However, the reason for this small but reproducible effect has not yet been clarified.

Because ERK or p38 inhibition prevents monocyte necrosis, we tested whether these MAP kinases were required for Rho glucosylation. THP-1 cells and normal monocytes were incubated in medium alone, or the presence of PD98059 $(20 \mu \mathrm{M})$, or SB203580 $(10 \mu \mathrm{M})$ for 30 minutes. Then cells were exposed to toxin A for 1 hour, and the ADP-ribosylation assay was performed on cell extracts. Neither inhibitor prevented toxin A-mediated Rho glucosylation in monocytes or in THP-1 cells (Figure 6b).

We tested whether the putative binding domain of toxin A may mediate monocyte activation using a 95$\mathrm{kDa}$ recombinant fragment carrying the $\mathrm{COOH}$-terminal repeating units of toxin A (provided as a GSTfusion protein by Scott Montcrief and David Lyerly, TechLab Inc., Blacksburg, Virginia, USA). However, this fragment did not activate IL-8 release in monocytes and did not prevent toxin A cytotoxic activity. This recombinant protein was also poorly soluble in PBS (data not shown).

Inbibition of $p 38$ prevents toxin A-induced neutrophil infiltration and enteritis in mice. C. difficile toxin A-induced p38 MAP kinase activation is required for IL-8 production, necrosis, and IL-1 $\beta$ release by monocytes in vitro. To assess the pathophysiological relevance of this in vitro model, we investigated whether the p38 inhibitor SB203580 might prevent toxin A-induced enteritis in mice. SB203580 (or its inactive analogue SB202474) was injected into the lumen of a 3-4-cm ileal loop (100 $\mu \mathrm{g} / \mathrm{loop}) 30$ minutes before toxin A administration. SB203580 prevented fluid secretion by $74 \%(P<0.001 ; n$ $=10$ ) whereas the inactive analog SB202474 had no significant effect $(P=0.4$; Figure $7 \mathrm{a})$. As evaluated by histology using scores for neutrophil infiltration, edema, and villous destruction, SB203580 reduced the severity of enteritis by $78 \%(P=0.005)$. Administration of SB202474 did not significantly prevent the signs of enteritis $(P=0.5$; Figure 7, b and c). Oral administration of SB203580 (20 $\mathrm{mg} / \mathrm{kg}) 30$ minutes before toxin challenge did not prevent enteritis (data not shown). These results indicate 


\section{Figure 5}

The ERK and $\mathrm{p} 38$ pathways mediate monocyte necrosis and IL-1 $\beta$ release induced by toxin A. Peripheral blood monocytes were isolated as described in Methods and incubated in medium alone, or the presence of the MEK inhibitor PD98059 (20 $\mu \mathrm{M})$, or the p38 inhibitor SB203580 (10 $\mu \mathrm{M})$ for 30 minutes. Then, C. difficile toxin A (40 nM) or $S$. aureus $\alpha$-toxin, a pore-forming toxin (10 nM), was added to the medium, and monocytes were incubated for an additional 90-120 minutes until more than $90 \%$ of the monocytes were necrotic in the control group. (a) As observed by phase-contrast microscopy $(\times 320)$, both toxins induced morphological features that characterized necrosis, including cell swelling, cytoplasmic translucence, and absence of nuclear fragmentation. PD98059 and SB203580 completely prevented the morphological features of necrosis induced by $C$. difficile toxin A, but not by $S$. aureus $\alpha$-toxin. (b, c) Dose-dependent effect of PD98059 and SB203580 on necrosis (b) and IL-1 $\beta$ release (c). Necrotic monocytes were counted by phase-contrast microscopy, and IL-1 $\beta$ was measured by ELISA in the supernatant. PD98059 and SB203580 each prevented toxin A-induced necrosis and IL-1 $\beta$ release with an $\mathrm{IC}_{50}$ of $1 \mu \mathrm{M}$ and $100 \mathrm{nM}$, respectively. However, they did not prevent necrosis or $\mathrm{IL}-1 \beta$ release induced by $S$. aureus $\alpha$-toxin. Means and SE of triplicates from a representative experiment are shown.

that p38 plays a key role in neutrophil recruitment and enteritis induced by $C$. difficile toxin A in vivo.

\section{Discussion}

This study shows that in human monocytic cells, ERK, and p38 MAP kinases are activated by C. difficile toxin A and are required for both IL-8 gene expression and cell necrosis. These results are consistent with recent studies showing that ERK and p38 upregulate IL- 8 production in response to proinflammatory cytokines or LPS $(29,30)$. To our knowledge, this is the first report that these MAP kinases mediate a pathway of cell necrosis. We have shown recently that monocyte necrosis is a regulated pathway of cell death mediated by caspaselike proteases and potassium depletion (19). This study indicates that ERK and p38 MAP kinases are specifically involved in necrosis induced by toxin A. Blocking the ERK and p38 pathways had no effect on monocyte necrosis induced by nigericin or staphylococcal $\alpha$-toxin. The ERK, p38, and JNK pathways have been implicated recently in the control of cell survival in response to various stresses in a cell- and stimulus-specific fashion. Apoptosis can be triggered by ERK inhibition $(31,32)$ or prevented by ERK inhibition $(33,34)$. Similarly, blocking p38 causes apoptosis in T-lymphocyte Jurkat cells (35), but prevents spontaneous apoptosis in neutrophils (36). The mechanisms whereby ERK and p38 MAP kinases mediate necrotic cell death in monocytes exposed to toxin A are still unclear. One possibility is that monocyte necrosis induced by toxin A may be mediated by cytotoxic oxidants. Activated monocytes can produce high levels of reactive oxygen species, and their production is controlled in part by ERK and p 38 through phospholipase A2 activation (37).

In monocytic cells exposed to toxin A, MAP kinase activation occurs very quickly (within 1 to 2 minutes), a
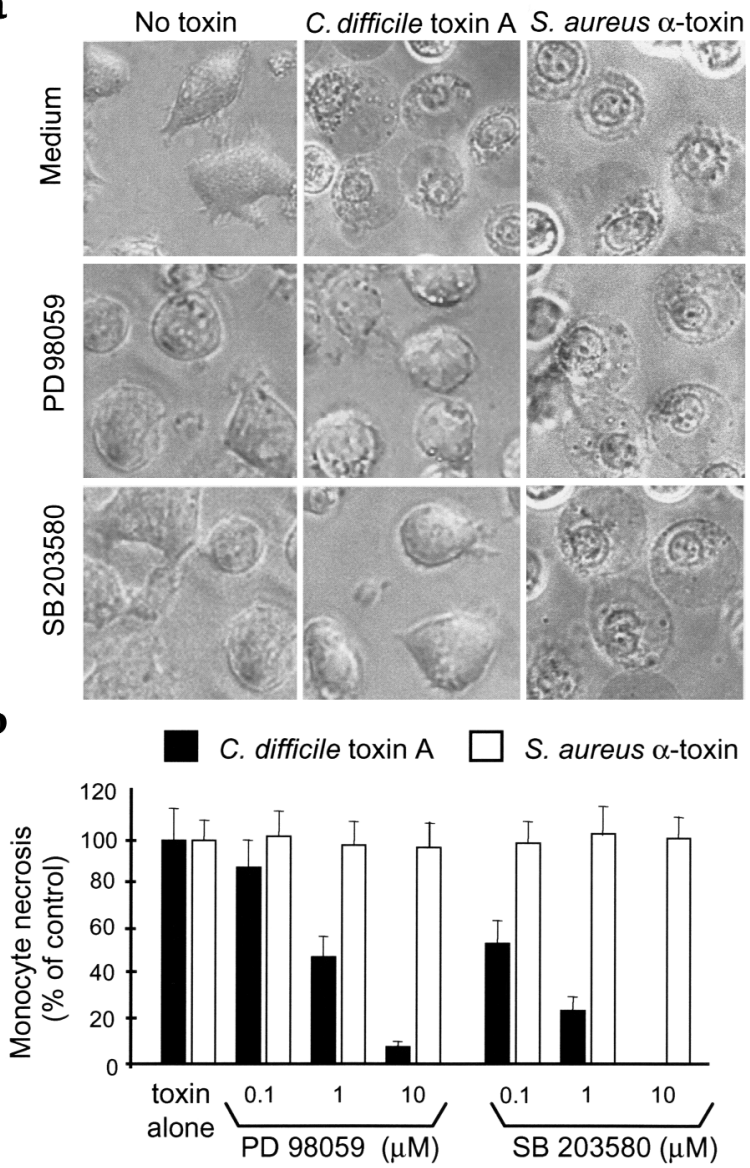

c
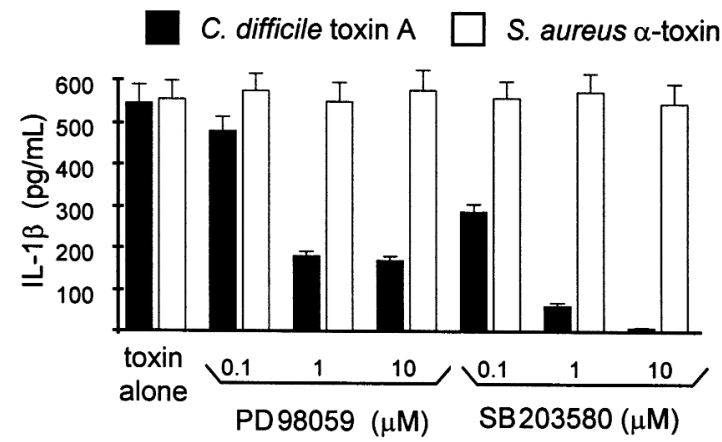

approximately 15 minutes before Rho protein glucosylation is evident. This time course supports the hypothesis that toxin's interaction with a cell-surface receptor may trigger MAP kinase activation. Rho glucosylation is detected later because this event is subsequent to toxin internalization and translocation into the cytoplasm. Thus, these findings suggest that initial MAP kinase activation may be independent of Rho glucosylation and raise the hypothesis that toxin $\mathrm{A}$-induced IL-8 production might be independent of its enzymatic activity. This hypothesis is supported by the fact that the active forms of the small GTP-binding proteins Rho, Cdc42, and Rac, which are substrates for toxin A, have been implicated in the activation of inflammatory cytokine gene transcription. For instance, $\mathrm{Cdc} 42$ and Rac have been shown to regulate p38 and JNK, where- 
as Rho, Cdc42, and Rac have been implicated in NF- $\mathrm{kB}$ activation. Dominant-negative mutants of Rho proteins or Rho inactivation by $C$. difficile toxins blocked the activation of NF- $\mathrm{KB}, \mathrm{p} 38$, JNK, and AP-1 (10-15, 21). Rho inactivation also blocked leukocyte adhesion through integrins (38), Fc $\gamma$ receptor signaling and phagocytosis in macrophages $(39$,$) and Fce receptor$ signaling in basophilic leukemia cells (8). Because Rho proteins appear to coordinate cytokine gene transcription in response to inflammatory stimuli, their inactivation by toxin $A$ would not be expected to trigger an inflammatory response. However, our data do not exclude a role for Rho glucosylation in IL-8 gene expression. For instance, early glucosylation of a subset of Rho proteins might induce MAP kinase activation, as caused by RhoA inactivation by C. botulinum $\mathrm{C} 3$ in Rat- 1 cells (40). The observation that toxin B is approximately 100 -fold more potent than toxin $\mathrm{A}$ in catalyzing Rho glucosylation (7) and 1,000-fold more potent in inducing monocyte IL-8 production (19) is in agreement with the later hypothesis. Experiments using enzymatically active recombinant toxin fragments are planned to test the effect of Rho glucosylation on MAP kinase signaling and IL-8 gene activation.

In a recent study by others (41), toxin $\mathrm{A}$ was found to activate NF- $\kappa B$ p50-p65 in monocytes. Furthermore, NF- $\mathrm{\kappa B}$ inhibitors blocked IL-8 production by toxin $\mathrm{A}$. These results are in agreement with our unpublished observations. This study also reports that toxin A-coated plates failed to activate monocytes and that toxin A-induced IL- 8 production was prevented by chloroquine and $\mathrm{NH}_{4} \mathrm{Cl}$. These 2 agents were shown to inhibit cytotoxicity in other cells. Based on these findings, the authors propose that toxin A internalization by monocytes is required for IL- 8 pro-

\section{Figure 6}

(a) Rho glucosylation is detected after MAP kinase activation by toxin A. The time course of Rho glucosylation was measured in THP-1 cells exposed to toxin $A(100 \mathrm{nM})$. After the indicated periods of time, cell extracts were incubated with $C$. botulinum $\mathrm{C} 3$ exoenzyme and $\left[{ }^{32} \mathrm{P}\right]$ NAD to ADP-ribosylate Rho. Proteins were then separated by $12 \%$ SDS-PAGE, and ADP-ribosylated Rho was measured by autoradiography and densitometry $(n=3)$. Rho glucosylation was detected 15-20 minutes after toxin A addition and was complete after 1 hour. Moreover, a 20\% increase in ADP-ribose incorporation was observed after 10 minutes of toxin exposure. Rho glucosylation was thus detected after MAP kinase activation that was evident after 1-2 minutes (Figure 1). (b) Rho glucosylation is independent of ERK and p38 activation. THP-1 cells and monocytes were pretreated with $20 \mu \mathrm{M}$ PD98059 or $10 \mu \mathrm{M}$ SB203580 for 30 minutes and then exposed to toxin $A$ for 1 hour. The ADP-ribosylation assay was performed as described above. Blocking the ERK and p38 pathways did not prevent Rho glucosylation by toxin A. duction. However, this study does not show that chloroquine and $\mathrm{NH}_{4} \mathrm{Cl}$ prevent toxin internalization, and the absence of effect on IL- 8 production by other stimuli was not shown. Moreover, it is not clear whether plastic-bound toxin A is able to bind or to cross-link membrane receptors. Therefore, these interesting results do not rule out our hypothesis that monocyte activation by toxin A may be mediated by binding to a membrane receptor.

In this study (Figure 6), we consistently detected a modest increase in ADP-ribose incorporation 10 minutes after toxin A exposure. The origin of this increase is unknown. Inactive GDP-bound Rho proteins are retained in the cytoplasm by guanidine nucleotide dissociation inhibitors (GDIs). It is currently accepted that Rho activation is associated with cleavage of the RhoGDI complex, followed by Rho translocation to the plasma membrane and GDP exchange for GTP. When complexed with GDIs, Rho cannot be ADP-ribosylated by C3 exoenzyme (42). Therefore, the early increase in ADP-ribosylation observed in cell lysates may result from Rho-GDI complex cleavage. Experiments are underway to examine this hypothesis.

This study indicates that the p38 MAP kinase inhibitor SB203580 prevents toxin A-induced enterotoxicity and inflammation. Prophylactic oral administration of SB203580 was shown previously to prevent cytokine production in models of chronic inflammation $(43,44)$. This, we believe, is the first demonstration that SB203580 has substantial anti-inflammatory effects in a model of acute intestinal inflammation. In a mouse model of endotoxin shock, oral administration of SB203580 $(20 \mathrm{mg} / \mathrm{kg}) 30$ minutes before LPS injection prevented the increases in plasma TNF- $\alpha$ levels and mortality (44). However, in this study oral

\section{a}
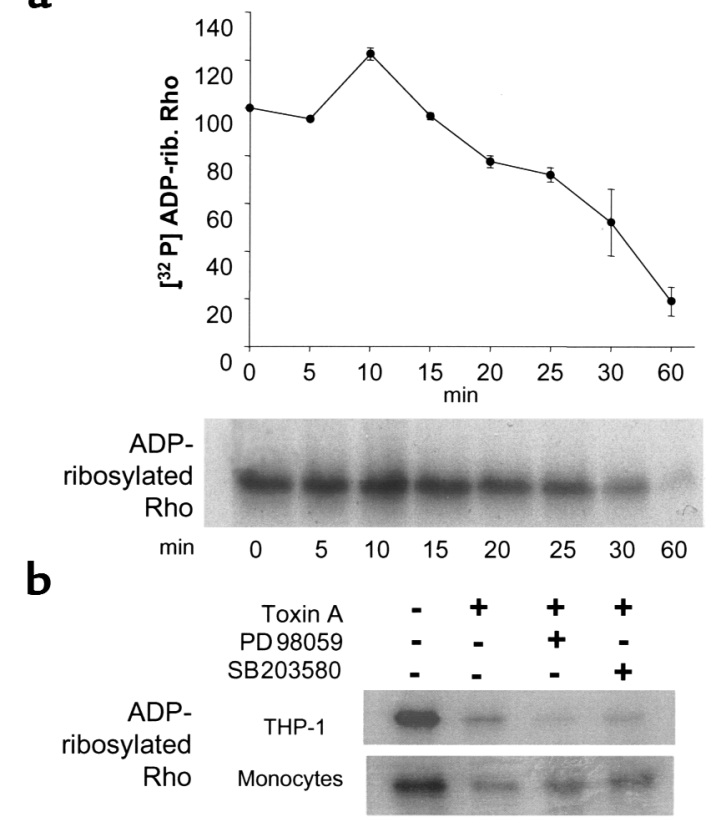
Figure 7

Inhibition of p38 MAP kinase prevents toxin A-induced enteritis in mouse ileum. The p38 inhibitor SB203580 or SB202474, a control compound inactive on p38 kinase activity $(100 \mu \mathrm{g} /$ loop $)$, was injected into the lumen of an ileal loop as described in Methods. After 30 minutes, toxin A $(10 \mu \mathrm{g})$ was administered, and animals were sacrificed 4 hours later. Loops were cut out and fluid secretion was assessed by measuring the weight/length ratio $(\mathrm{mg} / \mathrm{cm})$. Enteritis severity was measured by histology, using scores to quantify neutrophil infiltration, congestion, and villus destruction. (a, b) SB203580 inhibited toxin $\mathrm{A}$-induced fluid secretion by 74\% (a) $(P<0.001)$ and reduced enteritis severity by $78 \%(P=0.005)($ b $)$, whereas the inactive analog SB202474 had no significant effect (means and SE are shown; 9-10 loops per group). (c-f) Histological features of toxin $\mathrm{A}$-induced enteritis and their inhibition by SB203580. (c) Control ileum. (d) Toxin A alone causing destruction of villous architecture, neutrophil infiltration, edema, and ulceration. (e) SB203580 pretreatment preserved villous integrity, prevented neutrophil infiltration and ulceration, and partially inhibited edema. (f) SB202474 pretreatment was not protective.

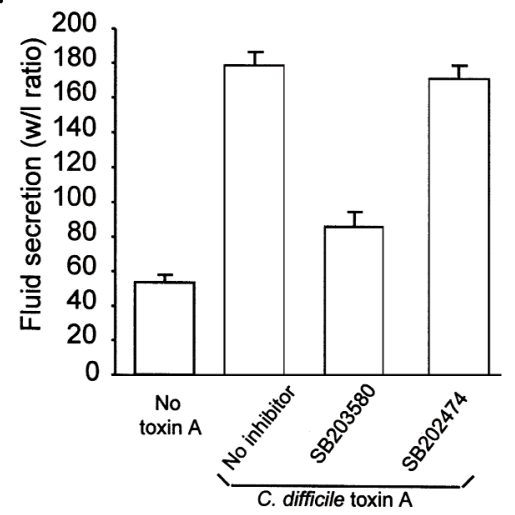

c

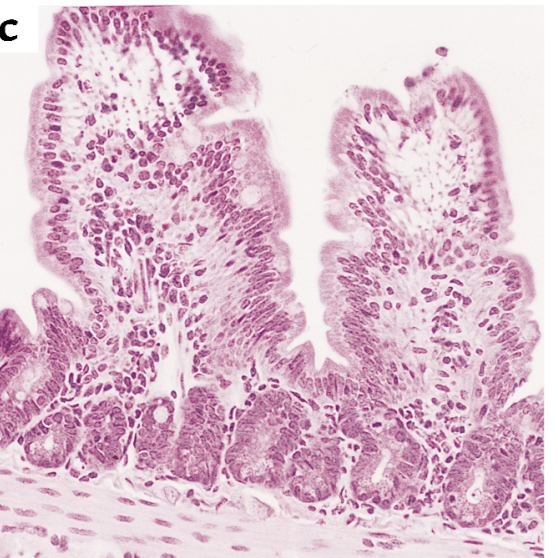

b
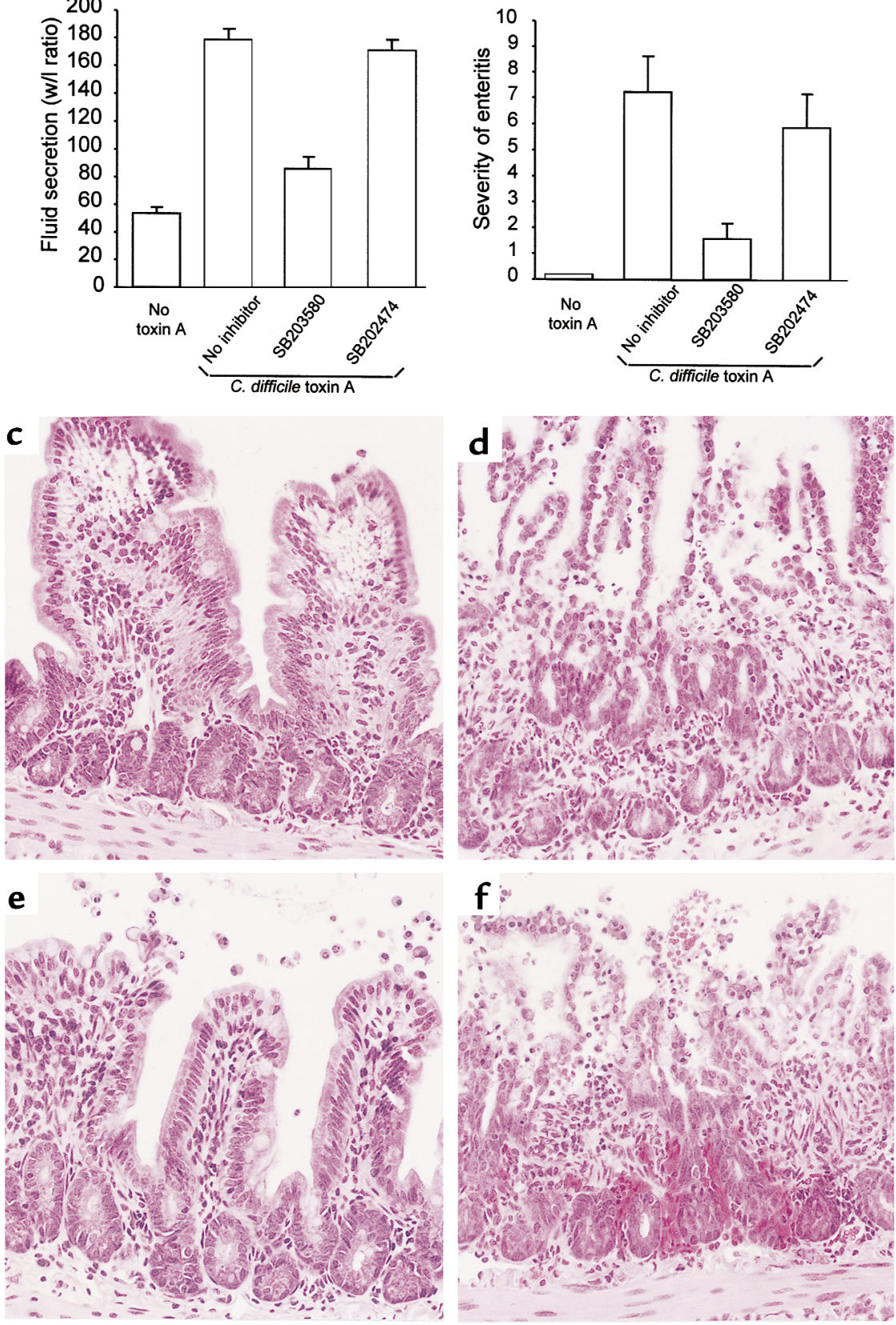

f

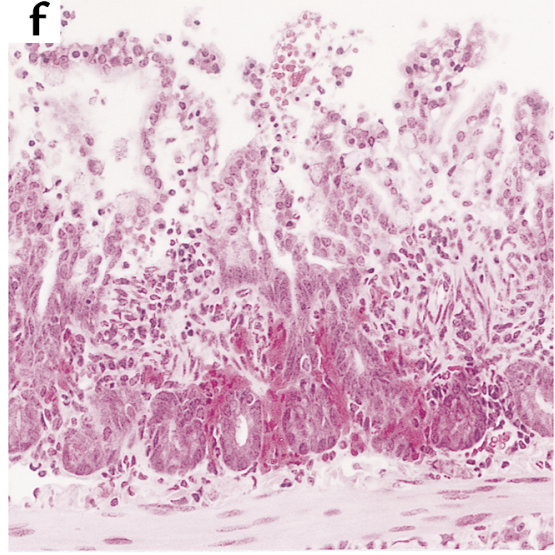

administration of SB203580 failed to prevent toxin A-induced colitis. Therefore, the anti-inflammatory effect observed after administration into the intestinal lumen may result from a local mucosal effect. In human colon mounted in Ussing chambers, C. difficile toxins have been shown to cause epithelial cell damage and detachment from the basal membrane (45). Because lamina propria macrophages are immediately adjacent to the epithelium, they might be directly stimulated by toxin $\mathrm{A}$ and toxin $\mathrm{B}$.

In summary, this study demonstrates that monocyte exposure to toxin A results in the rapid activation of MAP kinase-signaling pathways. ERK and p38 MAP kinases then mediate monocyte necrosis, IL-1 $\beta$ release, and IL-8 gene expression. MAP kinase activation precedes evident Rho glucosylation suggesting that cell activation might be independent of the intracellular enzymatic effects of toxin A. Activation of p38 MAP kinase also mediates intestinal inflammation and mucosal damage induced by toxin A. Based on these findings, we propose that the biological effects of C. difficile toxin A result from a combination of cell-surface activation events in addition to its intracellular glycosyltransferase activity.

\section{Acknowledgments}

M. Warny is the recipient of a Research Fellowship Award from the Crohn's and Colitis Foundation of 
America. A.C. Keates and I. Castagliuolo are recipients of Career Development Awards from the Crohn's and Colitis Foundation of America. This study was also supported by National Institutes of Health grant RO1DK-54920 (to C.P. Kelly), RO1DK-47343 (to C. Pothoulakis), and RO1DK-38583 (to J. T. LaMont).

1. Kelly, C.P., and LaMont, J.T. 1998. Clostridium difficile infection. Annu. Rev. Med. 49:375-390.

2. Kelly, C.P., et al. 1994. Neutrophil recruitment in Clostridium difficile toxin A enteritis in the rabbit. J. Clin. Invest. 93:1257-1265.

3. von Eichel-Streiber, C., Laufenberg-Feldmann, R., Sartingen, S., Schulze, J., and Sauerborn, M. 1990. Cloning of Clostridium difficile toxin B gene and demonstration of high $\mathrm{N}$-terminal homology between toxin A and B. Med. Microbiol. Immunol. 179:271-279.

4. Just, I., et al. 1995. The enterotoxin from Clostridium difficile (ToxA) monoglucosylates the Rho proteins. J. Biol. Chem. 270:13932-13936.

5. Just, I., et al. 1995. Glucosylation of Rho proteins by Clostridium difficile toxin B. Nature. 375:500-503.

6. Hofmann, F., Bush, C., Prepens, U., Just, I., and Aktories, K. 1997. Localization of the glycosyltransferase activity of Clostridium difficile toxin B to the N-terminal part of the holotoxin. J. Biol. Chem. 272:11074-11078.

7. Chaves-Olarte, E., Weidmann, M., von Eichel-Streiber, C., and Thelestam, M. 1997. Toxin A and B from Clostridium difficile differ with respect to enzymatic potencies, cellular substrate specificities and surface binding to cultured cells. J. Clin. Invest. 100:1734-1741.

8. Prepens, U., Just, I., von Eichel-Streiber, C., and Aktories, K. 1996. Inhibition of FceRI-mediated activation of rat basophilic leukemia cells by Clostridium difficile toxin B (monoglucosyltransferase). J. Biol. Chem. 271:7324-7329.

9. Schmidt, M., Rumenapp, U., Bienek, C., Keller, J., von Eichel-Streiber, C., and Jakobs, K.H. 1996. Inhibition of receptor signaling to phospholipase D by Clostridium difficile toxin B. J. Biol. Chem. 271:2422-2426.

10. Pan, Z.K., et al. 1998. Role of Rho GTPase in bradykinin-stimulated nuclear factor-kB activation and IL- $1 \beta$ gene expression in cultured human epithelial cells. J. Immunol. 160:3038-3045.

11. Wesselborg, S., Bauer, M., Vogt, M., Schmitz, M., and Schulze-Osthoff, K. 1998. Activation of transcription factor NF-kB and p38 mitogen-activated protein kinase is mediated by distinct and separate stress effector pathways. J. Biol. Chem. 272:12422-12429.

12. Naumann, M., Rudel, T., Wieland, B., Bartsch, C., and Meyer, T.F. 1998. Coordinate activation of activator protein 1 and inflammatory cytokines in response to neisseria gonorrhoeae epithelial cell contact involves stress response kinases. J. Exp. Med. 188:1277-1286.

13. Zhang, S., et al. 1995. Rho family GTPases regulate p38 mitogen-activated protein kinase through the downstream mediator Pak1. J. Biol. Chem. 270:23934-23936.

14. Montaner, S., Perona, R., Saniger, L., and Lacal, J.C. 1998. Multiple signaling pathways lead to the activation of the nuclear factor $\mathrm{kB}$ by the Rho family of GTPases. J. Biol. Chem. 273:12779-12785.

15. Perona, R., et al. 1997. Activation of the nuclear factor-kB by Rho, CDC42 and Rac-1 proteins. Genes Dev. 11:463-475

16. Miller, P.D., Pothoulakis, C., Baeker, T.R., LaMont, J.T., and Rothstein, T.L. 1990. Macrophage-dependent stimulation of T cell depleted spleen cells by C. difficile toxin A and calcium ionophore. Cell Immunol. 126:155-163.

17. Flegel, W.A., et al. 1991. Cytokine response by human monocytes to Clostridium difficile toxin A and toxin B. Infect. Immun. 59:3659-3666.

18. Linevsky, J.K., et al. 1997. IL-8 release and neutrophil activation by Clostridium difficile toxin-exposed monocytes. Am. J. Physiol. 273:G1333-G1340.

19. Warny, M., and Kelly, C.P. 1999. Monocytic cell necrosis is mediated by potassium depletion and caspase-like proteases. Am. J. Physiol. 276:C717-C724.

20. Kyriakis, J.M., and Avruch, J. 1996. Sounding the alarm: protein kinase cascades activated by stress and inflammation. J. Biol. Chem. 271:24313-24316

21. Han, J., Lee, J.D., Bibbs, L., and Ulevitch, R.J. 1994. A MAP kinase targeted by endotoxin and hyperosmolarity in mammalian cells. Science. 265:808-811.

22. Lee, J.C., et al. 1994. A protein kinase involved in the regulation of inflam- matory cytokine biosynthesis. Nature. 372:739-746.

23. Kyriakis, J.M., et al. 1994. The stress-activated protein kinase subfamily of c-Jun kinases. Nature. 369:156-160.

24. Sullivan, N.M., Pellett, S., and Wilkins, T.D. 1982. Purification and characterization of toxins $\mathrm{A}$ and $\mathrm{B}$ of Clostridium difficile. Infect. Immun. 35:1032-1040.

25. Pothoulakis, C., et al. 1994. CP-96,345, a substance P antagonist, inhibits rat intestinal responses to Clostridium difficile toxin A but not cholera toxin. Proc. Natl. Acad. Sci. USA. 91:947-951.

26. Jiang, Y., et al. 1996. Characterization of the structure and function of a new mitogen-activated protein kinase (p38ß). J. Biol. Chem. 271:17920-17926.

27. Enslen, H., Raingeaud, J., and Davis, R.J. 1998. Selective activation of p38 mitogen-activated protein (MAP) kinases isoforms by the MAP kinase kinases MKK3 and MKK6. J. Biol. Chem. 273:1741-1748.

28. Jiang, Y., et al. 1997. Characterization of the structure and function of the fourth member of p38 group of mitogen activated protein kinases, p38 delta. J. Biol. Chem. 272:30122-30128.

29. Holtmann, H., et al. 1999. Induction of interleukin-8 synthesis integrates effects on transcription and mRNA degradation from at least three different cytokine- or stress-activated signal transduction pathways. Mol. Cell. Biol. 19:6742-6753.

30. Scherle, P.A., et al. 1998. Inhibition of MAP kinase kinase prevents cytokine and prostaglandin E2 production in lipopolysaccharide-stimulated monocytes. J. Immunol. 161:5681-5686.

31. Xia, Z., Dickens, M., Raingeaud, J., Davis, R.J., and Greenberg, M.E. 1995. Opposing effects of ERK and JNK-p38 MAP kinases on apoptosis. Science. 270:1326-1331.

32. Berra, E., Diaz-Meco, M.T., and Moscat, J. 1998. The activation of p38 and apoptosis by the inhibition of Erk is antagonized by the phosphoinositide 3-kinase/Akt pathway. J. Biol. Chem. 273:10792-10797.

33. Goillot, E., et al. 1997. Mitogen-activated protein kinase-mediated Fas apoptotic signaling pathway. Proc. Natl. Acad. Sci. USA. 94:3302-3307.

34. Murray, B., Alessandrini, A., Cole, A.J., Yee, A.G., and Furshpan, E.J. 1998. Inhibition of the $\mathrm{p} 44 / \mathrm{p} 42 \mathrm{MAP}$ kinase pathways protects hippocampal neurons in a cell-culture model of seizure activity. Proc. Natl. Acad. Sci. USA. 95:11975-11980.

35. Nemoto, S., Xiang, J., Huang, S., and Lin, A. 1998. Induction of apoptosis by SB202190 through inhibition of p38 beta mitogen-activated protein kinase. J. Biol. Chem. 273:16415-16420.

36. Aoshiba, K., Yasui, S., Hayashi, M., Tamaoki, J., and Nagai, A. 1999. Role of p38-mitogen-activated protein kinase in spontaneous apoptosis of human neutrophils. J. Immunol. 162:1692-1700.

37. Leslie, C.C. 1997. Properties and regulation of cytosolic phospholipase A2. J. Biol. Chem. 272:16709-16712.

38. Laudana, C., Campbell, J.J., and Butcher, E.C. 1996. Role of Rho in chemoattractant-activated leucocyte adhesion through integrins. Science. 271:981-983

39. Hackam D.J., Rotstein, O.D., Schreiber, A., Zhang, W.J., and Grinstein, S. 1997. Rho is required for the initiation of calcium signaling and phagocytosis by Fcgamma receptors in macrophages. J. Exp. Med. 186:955-966.

40. Beltman, J., Erickson, J. R., Martin, G.A., Lyons, J.F., and Cook, J. 1999. C3 toxin activates the stress signaling pathways, JNK and p38, but antagonizes the activation of AP-1 in Rat-1 cells. J. Biol. Chem. 274:3772-3780.

41. Jefferson, K.K., Smith M.F., Jr., and Bobak, D.A. 1999. Roles of intracellular calcium and NF-kappa B in the Clostridium difficile toxin A-induced upregulation and secretion of IL-8 from human monocytes. J. Immunol. 163:5183-5191.

42. Kikuchi, A., et al. 1992. Functional interactions of stimulatory and inhibitory GDP/GTP exchange proteins and their common substrate small GTP-binding protein. J. Biol. Chem. 267:14611-14615.

43. Badger, A.M., et al. 1998. SB203580 inhibits p38 mitogen-activated protein kinase, nitric oxide production, and inducible nitric oxide synthase in bovine cartilage-derived chondrocytes. J. Immunol. 161:467-473.

44. Badger, A.M., et al. 1996. Pharmacological profile of SB 203580, a selective inhibitor of cytokine suppressive binding protein/p38 kinase, in animal models of arthritis, bone resorption, endotoxin shock and immune function. J. Pharmacol. Exp. Ther. 279:1453-1461.

45. Riegler, M., et al. 1995. Clostridium difficile toxin B is more potent than toxin A in damaging human colonic epithelium in vitro. J. Clin. Invest. 95:2004-2011. 